DOI: $10.2478 /$ ace-2013-0028

\title{
COMPACTION AND LIQUEFACTION OF A SANDY LAYER: SIMULATION OF SHAKING TABLE EXPERIMENTS
}

\begin{abstract}
A. SAWICKI ${ }^{1}$ W. ŚWIDZIŃSKI²
Abstract: This paper presents numerical simulations of the behavior of a sandy layer subjected to a cyclic horizontal acceleration in shaking table tests, with a particular attention focused on the settlements of a dry sand layer, and on the liquefaction of saturated sand. A compaction/liquefaction model $(\mathrm{C} / \mathrm{L})$ is applied to these simulations. The influence of specific parameters of the model on the compaction and liquefaction of a sandy layer is shown and discussed. The results of simulations are compared with selected experimental data.
\end{abstract}

Key words: sandy layer, compaction, liquefaction, seismic table.

\section{INTRODUCTION}

This paper deals with numerical simulations of the response of a sandy layer to a cyclic horizontal acceleration in shaking table tests. Such tests are performed to study the behaviour of various structures and grounds in seismic regions, see FUKUTEKE et al., [1], Matsuo et al., [2], Moretti et al., [3], Prasad et al., [4], Seed et al., [5], Towhata et al. (1999), [6], UeNG et al., [7]. It is important to understand the dynamics of a sandy layer for at least two reasons. First, such layers often appear in nature as subsoils for civil engineering structures, which means that their behaviour has practical importance, among others, for economic purposes or the safety of infrastructure. Dry sands, or saturated ones, but in free draining conditions, compact when subjected to seismic excitations, which results in excessive settlements. Saturated sands in undrained conditions liquefy, which leads to catastrophic events such as, for example, the sinking of structures, massive landslides, etc. Second, a sandy layer can be modeled by a relatively simple mechanical scheme, which makes theoretical and numerical analyses efficient.

The aim of this paper is to compare the results of numerical simulations of the dynamics of a sandy layer, tested on the shaking table, with laboratory measurements. The first group of simulations represents the behaviour of a dry sand layer - mainly

1 Institute of Hydro-Engineering, IBW PAN, Kościerska 7, 80-382 Gdańsk, Poland, email: as@ibwpan.gda.pl

2 Institute of Hydro-Engineering, IBW PAN, Kościerska 7, 80-382 Gdańsk, Poland, email: waldek@ibwpan.gda.pl, (Corresponding author). 
seismic-induced settlements. The second group comprises simulations of the liquefaction of a saturated soil layer. The phenomena of compaction, pore pressure generation, and subsequent liquefaction are studied by means of a compaction/liquefaction model $(\mathrm{C} / \mathrm{L})$ that has been developed in the Institute of Hydro-Engineering, see SAwICKI, [8]. The model was calibrated in the laboratory for the model sand "Gdynia," that is, the parameters used in the $\mathrm{C} / \mathrm{L}$ model had been determined for this sand.

Numerical simulations show the influence of certain soil parameters, such as the shear modulus and compaction characteristics, on the settlements of the layer. The influence of the amplitude of horizontal acceleration on settlements is also shown. The other simulations illustrate the development of an excess pore pressure in the layer immediately before its liquefaction, as well as the influence of the shear modulus and the amplitude of cyclic acceleration on the number of loading cycles to liquefaction. The results of numerical simulations show that the $\mathrm{C} / \mathrm{L}$ model can reproduce the averaged behavior of a sandy layer tested on the shaking table.

\section{Formulation OF THE COMPACTION PROBLEM}

Figure 1 shows a sandy layer tested on the shaking table. The layer is placed in an aquarium that is fixed to the table. The dimensions of the layer are following: length $L=50 \mathrm{~cm}$ and depth $H=16 \mathrm{~cm}$, SAwicki et al., [9]. The layer is subjected to horizontal shaking with controlled acceleration. In this paper, harmonic acceleration is considered:

$$
A=A_{0} \sin \omega t,
$$

where $\omega$ denotes the angular frequency of shaking, $A_{0}$ is the amplitude of acceleration, $t$ denotes time.

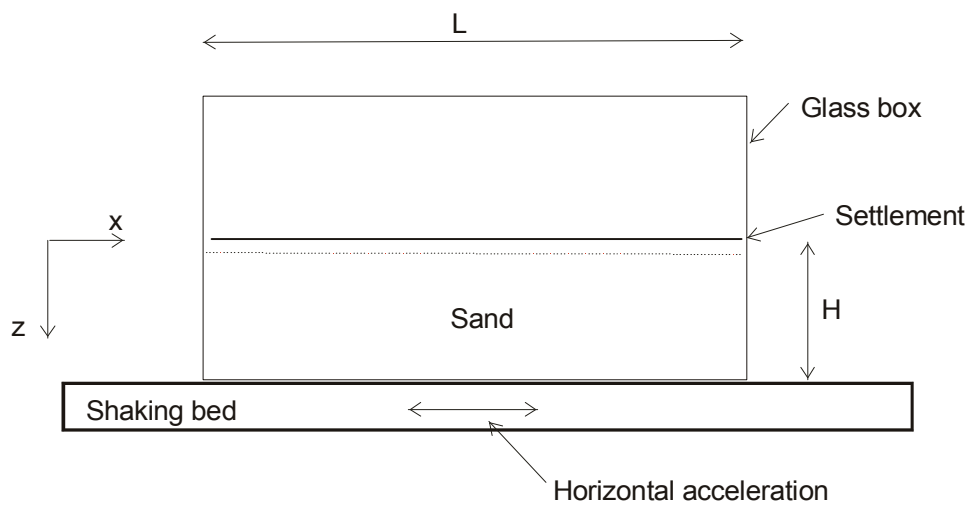

Fig. 1. Geometry of a sandy layer 
SAwICKI et al., [9] discussed boundary conditions for the above problem and presented a statically/dynamically admissible stress field:

$$
\sigma_{z}=\gamma_{s} z, \sigma_{x}=K_{0} \gamma_{s} z
$$

$$
\tau=\rho A z,
$$

where: $\sigma_{z}=$ vertical stress, $\sigma_{x}=$ horizontal stress, $\tau=$ shear stress, $K_{0}=$ coefficient of lateral pressure, $\gamma_{s}=$ unit weight of the sand, $\rho=\gamma_{s} / g=$ density of the sand, $g=$ gravity acceleration, $z=$ vertical coordinate measured downwards from the upper surface, $x$-horizontal co-ordinate, see Figure 1.

The above stress field should not exceed the Coulomb-Mohr yield condition, i.e.

$$
f=\left(\sigma_{z}-\sigma_{x}\right)^{2}-\left(\sigma_{z}+\sigma_{x}\right)^{2} \sin ^{2} \varphi+4 \tau^{2} \leq 0,
$$

where $\varphi$ denotes the angle of internal friction.

If the level of horizontal acceleration is large, i.e. when the Coulomb-Mohr yield condition is reached, the soil adapts to this new state because the so-called seismicinduced lateral stresses are generated. This phenomenon can be modeled by an increase of $K_{0}$ according to the following formula:

$$
\left(\frac{A}{g}\right)^{2} \leq \frac{1}{4}\left[\left(1+K_{0}\right)^{2} \sin ^{2} \varphi-\left(1-K_{0}\right)^{2}\right] .
$$

Note that in the model considered, only the shear stress (3) is cyclic, whereas normal stresses (2) are geostatic. This fact greatly simplifies further analysis of compaction. Having known $\tau$, the corresponding shear strain $\gamma$ can be determined from the formula

$$
\gamma=\tau / G
$$

where $G$ denotes the shear modulus, which has the following form:

$$
G=G_{0}+G_{1} \sqrt{p^{\prime}},
$$

where $G_{0}=$ residual shear modulus, $G_{1}=$ parameter, $p^{\prime}=$ effective mean stress, which is equal to the total mean stress in the case of a dry layer:

$$
p^{\prime}=p=\left(\sigma_{z}+2 \sigma_{x}\right) / 3 .
$$


Then, the soil compaction $\Phi$ can be determined from the following constitutive equation (SAWICKI \& ŚWIDZIŃSKI, [10]):

$$
\Phi=C_{1} \ln \left(1+C_{2} \zeta\right),
$$

where

$$
\zeta=\frac{1}{4} \gamma_{0}^{2} N,
$$

and

$\gamma_{0}=$ cyclic shear strain amplitude, $N=$ number of loading cycles treated as a continuous variable, $C_{1}$ and $C_{2}=$ parameters determined from cyclic simple shear tests. The compaction $\Phi$ is defined as a relative porosity change:

$$
\Phi=\frac{n_{0}-n}{n_{0}},
$$

where $n=$ current porosity, $n_{0}=$ initial porosity. Compaction is related to the volumetric strain $\varepsilon_{v}$ by the following formula:

$$
\varepsilon_{v}=\frac{n_{0}}{1-n_{0}} \Phi .
$$

Note that in the case considered, the volumetric strain equals the vertical strain, i.e. $\varepsilon_{v}=\varepsilon_{z}$.

The above equations are sufficient to determine the settlements of a sandy layer subjected to an arbitrary history of horizontal acceleration, but we shall take into account only harmonic excitements.

\section{Numerical Simulations of SETtLements}

The above equations are uncoupled, which means that we do not have to solve the boundary-value problem at each stage of numerical simulations. In this case, a simplified procedure for an efficient analysis of the problem considered, leads to the algorithm presented below. Note that the problem is one-dimensional, as the layer's behavior depends only on the vertical co-ordinate $z$. In the vicinity of the vertical walls of the aquarium, the stress state is more complicated, but when the layer is "thin," i.e. when the ratio $H / L$ is small, the above stress state applies in the middle part of the layer, neglecting local disturbances. Figure 2 shows the division of the sandy layer into sublayers. The behavior of each separate layer can be treated independently, and then, their partial effects can be integrated. 


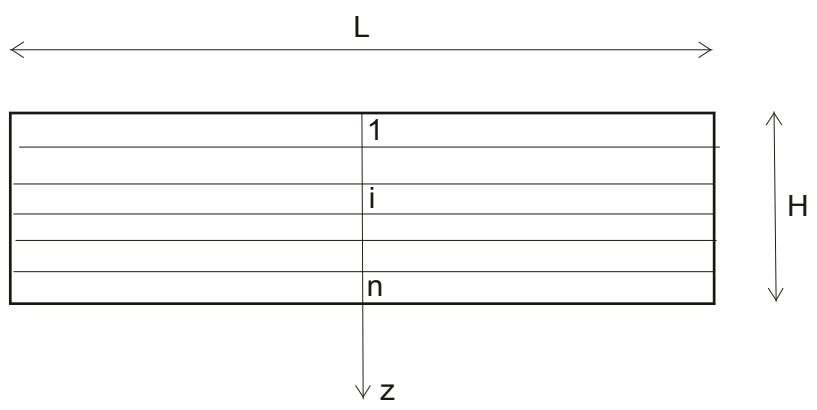

Fig. 2. Division of a sandy layer into sublayers

The algorithm of the analysis is following:

1. The determination of soil properties i.e. including its physical and mechanical properties - the calibration of the model. The determination of stress and strain states in the middle of each layer for a given history of a seismic excitation.

2. The determination of the soil compaction and settlement of each layer.

3. The integration of partial settlements to obtain the total settlement of the sandy layer.

The starting point for numerical simulations are the following values of the "Gdynia" sand parameters obtained from independent laboratory investigations, see Sawicki et al., [11].

- Initial porosity $n=0.38$

- Unit weight of water $\gamma_{w}=0.098 \times 10^{5} \mathrm{~N} / \mathrm{m}^{3}$;

- Unit weight of solid grains $\gamma_{s}=0.265 \times 10^{5} \mathrm{~N} / \mathrm{m}^{3}$;

- Unit weight of fully saturated soil $\gamma_{\text {sat }}=0.2 \times 10^{5} \mathrm{~N} / \mathrm{m}^{3}$;

- Coefficient of the earth pressure at rest $K_{0}=0,5$. It follows from the classical formula;

- Elastic modulus of the sand $E=2.85 \times 10^{8} \mathrm{~N} / \mathrm{m}^{2}$ (determined from oedometric tests);

- Poisson's ratio $v=0.16$ (determined from oedometric tests);

- Compressibility of the soil skeleton $\kappa=0.72 \times 10^{-8} \mathrm{~m}^{2} / N$ (determined from oedometric test);

- Parameters of the $\mathrm{C} / \mathrm{L}$ model for loose sand: $D_{1}=0.5, D_{2}=0.11$. They correspond to the stress unit $10^{5} \mathrm{~N} / \mathrm{m}^{2}$ and the strain unit $10^{-3}$;

- Initially $G_{1}=0.7$, which follows from triaxial investigations. After theoretical analysis it was shown that it should be 0.01 . The unit of $G$ is $10^{8} \mathrm{~N} / \mathrm{m}^{2}$. 


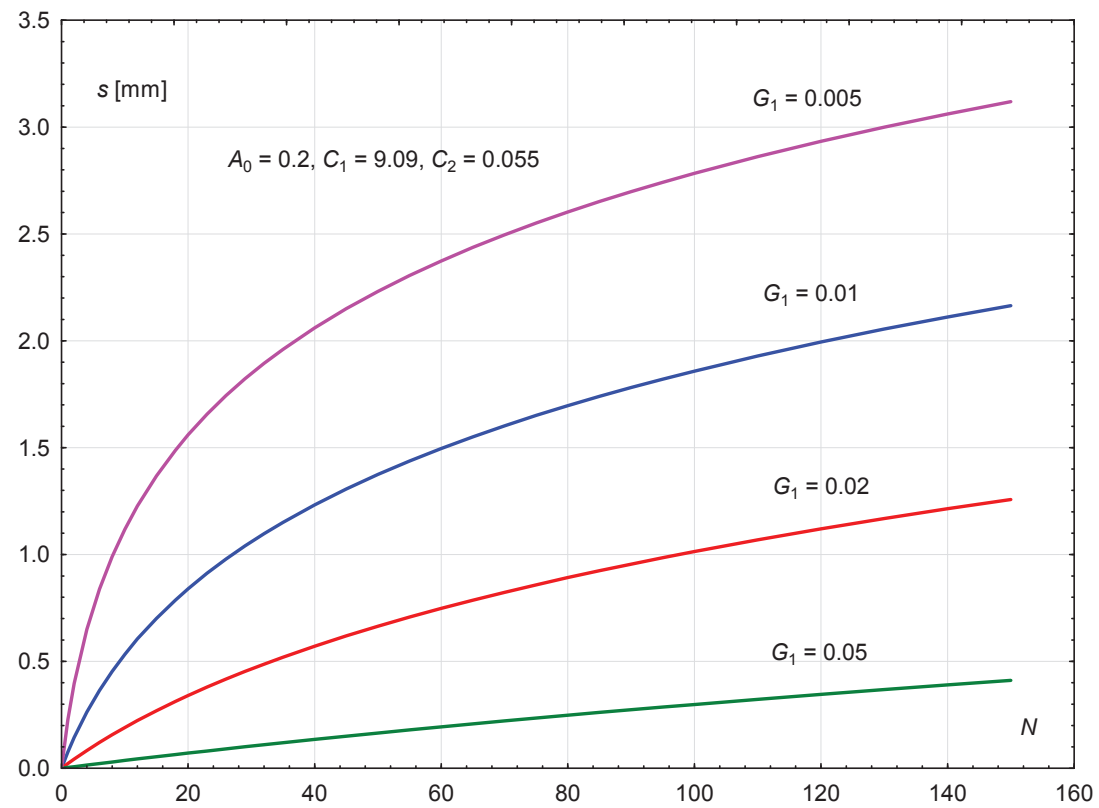

Fig. 3. Development of settlements as functions of the number of loading cycles for various values of the shear modulus

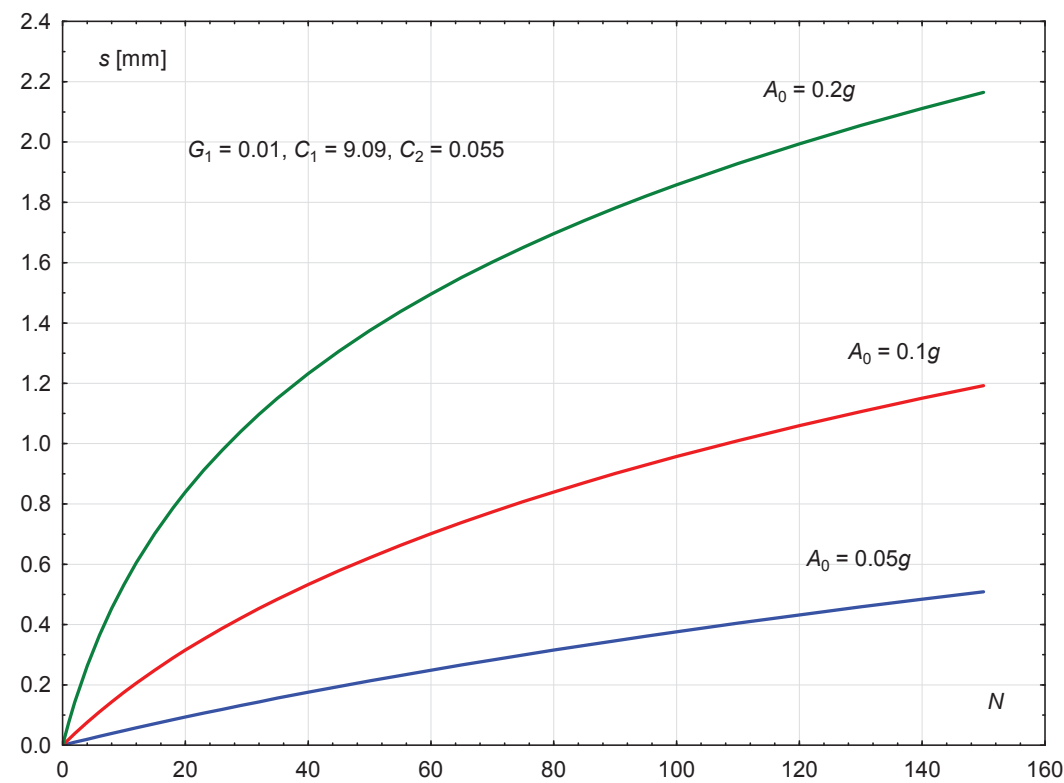

Fig. 4. Settlements of the layer as functions of the number of loading cycles or various acceleration amplitudes 


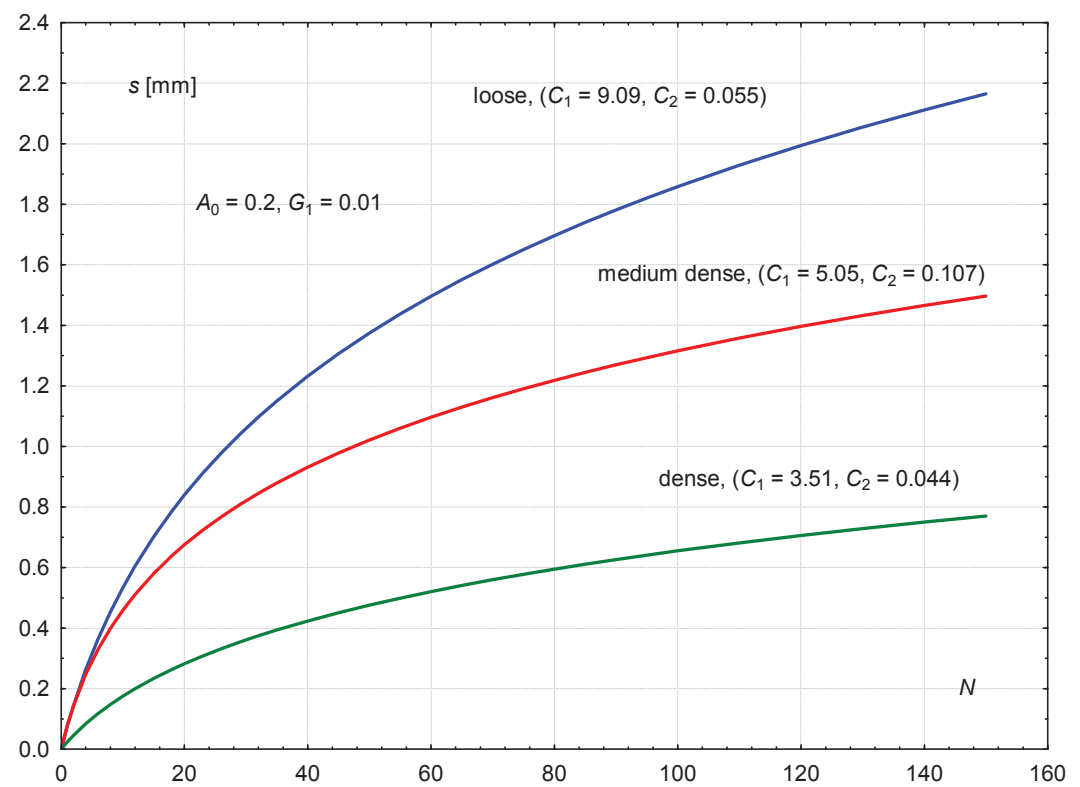

Fig. 5. Settlements as functions of the number of loading cycles for various initial densities

Some results of numerical simulations are shown in Figures 3-5. Figure 3 shows the influence of the shear modulus on the development of the settlements of loose sand $\left(C_{1}=9.09, C_{2}=0.0055\right)$ subjected to a horizontal cyclic acceleration of the amplitude $A_{0}=0.2 \mathrm{~g}$. Settlements increase with decreasing values of $G_{1}$ as cyclic shear strain amplitudes become larger which, in turn, strongly influences the compaction of sand, see Eqs. (2.6-2.10). The best fit to experimental data is obtained for $G_{1}=0.01$, as the measured value of settlement after $\mathrm{N}=120$ cycles was $2 \mathrm{~mm}$. Recall that the behavior of a sandy layer tested on the shaking table corresponds to very small effective stresses, which strongly influence the shear modulus. To determine the shear modulus for such low stresses is a very difficult experimental task, see SAwICKI et al., [12].

Figure 4 illustrates the development of the settlements of the same loose sand as functions of the amplitudes of horizontal shaking, and Figure 5 shows the influence of the initial state of sand (loose, medium dense, dense) on settlements. This state is defined by the values of the coefficients $C_{1}$ and $C_{2}$ shown in Figure 5. The results shown in Figures 4 and 5 are consistent with experimental observations, as larger amplitudes of acceleration cause larger settlements, and loose sand compacts more than the dense one. The $\mathrm{C} / \mathrm{L}$ model makes it possible to simulate these settlements both qualitatively and quantitatively. 


\section{Formulation of the LiQUefaction PROBLEM}

A layer of saturated sand in the aquarium is considered. The total stresses consist of two parts, namely the effective stresses, distinguished by prime, and the pore pressure $u$ :

$$
\begin{gathered}
\sigma_{z}=\sigma_{z}^{\prime}+u, \\
\sigma_{x}=\sigma_{x}^{\prime}+u, \\
\tau=\tau^{\prime} .
\end{gathered}
$$

Note that the vertical total stress is given by the following relation:

$$
\sigma_{z}=\gamma_{s a t} z
$$

where

$$
\gamma_{s a t}=n \gamma_{w}+(1-n) \gamma_{s}
$$

denotes the own weight of saturated sand, whereas $\gamma_{w}$ and $\gamma_{s}$ denote unit weights of pore water and solid grains respectively.

The initial pore pressure distribution is hydrostatic, i.e.

$$
u=u_{0}=\gamma_{w} z .
$$

Therefore, the vertical effective stress is following:

$$
\sigma_{z}^{\prime}=(1-n)\left(\gamma_{s a t}-\gamma_{w}\right) z .
$$

The other stresses are given by the following formulae:

$$
\begin{gathered}
\sigma_{x}^{\prime}=K_{0} \sigma_{z}^{\prime}, \\
\tau=\rho_{s} A z,
\end{gathered}
$$

where $\rho_{s}=\gamma_{s} / g$ is the density of fully saturated soil.

The cyclic shear stress (4.9) generates the pore pressure, which is described by the following constitutive equation: 


$$
\begin{gathered}
\frac{d u}{d N}=\frac{D_{1} \gamma_{0}^{2}}{4 a} \exp \left(-D_{2} a u\right), \\
a=\frac{1-n}{n} \kappa,
\end{gathered}
$$

where $D_{1}=C_{1} C_{2}, D_{2}=1 / C_{1}$, and $\kappa$ denotes the elastic compressibility of the soil skeleton. The quantity

$$
\gamma_{0}=\frac{\tau_{0}}{G}
$$

denotes the cyclic shear stress amplitude.

The algorithm is following:

1. The determination of soil parameters, initial stresses, etc.

2. The determination of the increment in excess pore pressure for the increment $d N$. These increments will be replaced by the finite increments $\Delta u, \Delta N$ in Eq. (4.10). This should be done for each layer from Figure 2 .

3. The determination of the actual effective stresses and the new shear modulus. Checking the Coulomb-Mohr failure criterion and changing $K_{0}$ if necessary.

4. The next step of a similar procedure, up to the liquefaction of particular layers.

Figures 6-9 show simple simulations of the behavior of a saturated sand layer subjected to a cyclic horizontal acceleration. Figure 6 illustrates the process of pore pressure generation for subsequent loading cycles. The boundary line on the RHS of this figure corresponds to the initial distribution of the mean effective stress $p_{0}^{\prime}$. The lines inside the region bounded by the line $p_{0}^{\prime}$ and the $z$ axis show the distribution of excess pore pressures for subsequent loading cycles. The layer liquefies for $N \approx 7.2$ cycles as the difference $p_{0}^{\prime}-u_{\text {excess }} \approx 0$, which corresponds to the liquefaction criterion $p^{\prime}=0$. Figure 7 shows the process of pore pressure generation at the base of the layer for the data from Figure 6.

Figure 8 illustrates the influence of the acceleration amplitude on the number of loading cycles to liquefaction $N_{L}$ for initially loose sand and the shear modulus $G_{1}=0.05$ (recall the units, see Eq. 2.7). The corresponding curve has a hyperbolic shape, showing a strong influence of the harmonic input on the liquefaction of the layer. Figure 9 shows the influence of the shear modulus on $N_{L}$, which has a parabolic shape. The curves presented in Figures 8 and 9 show that the $\mathrm{C} / \mathrm{L}$ model reasonably describes liquefaction properties of a sandy layer, as stronger input leads to more rapid liquefaction, and a stronger sand (larger $G_{1}$ ) liquefies slower than a weaker one. Some comment is necessary regarding the development of excess pore pressures shown in Figure 6. The shape of the consecutive curves illustrating the distribution of 


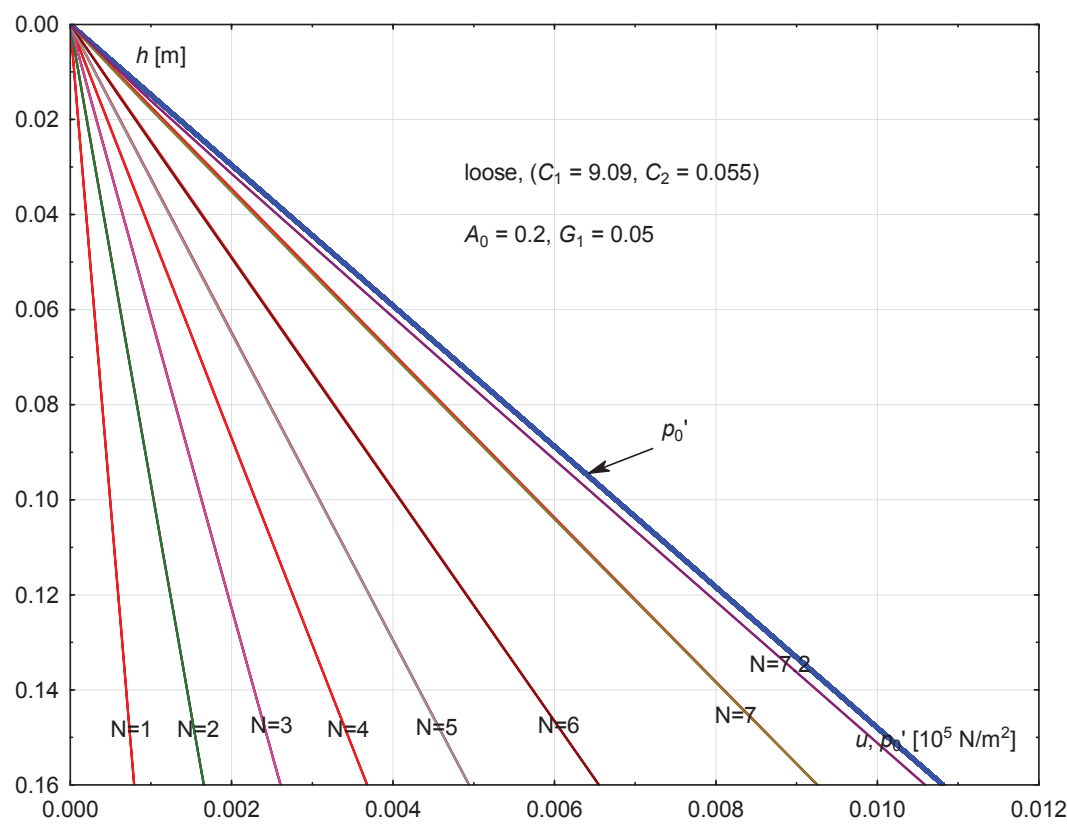

Fig. 6. Generation of pore water pressure in a sandy layer

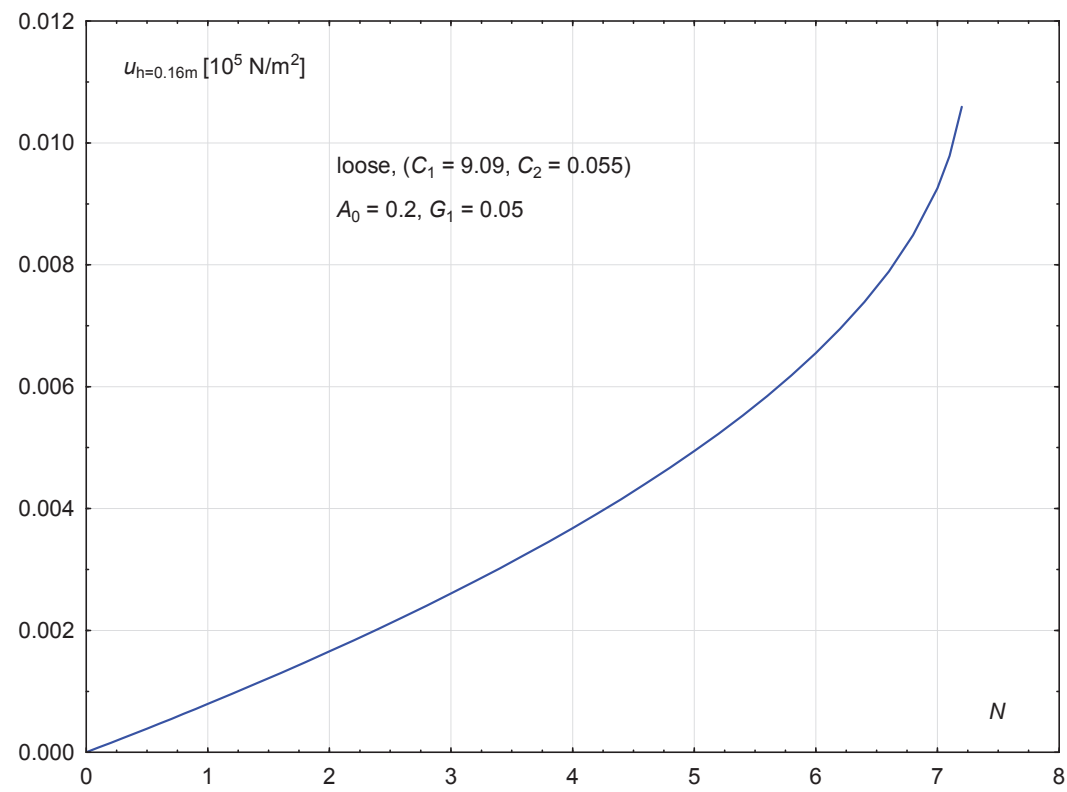

Fig. 7. Generation of pore water pressure at the bottom of a sandy layer 


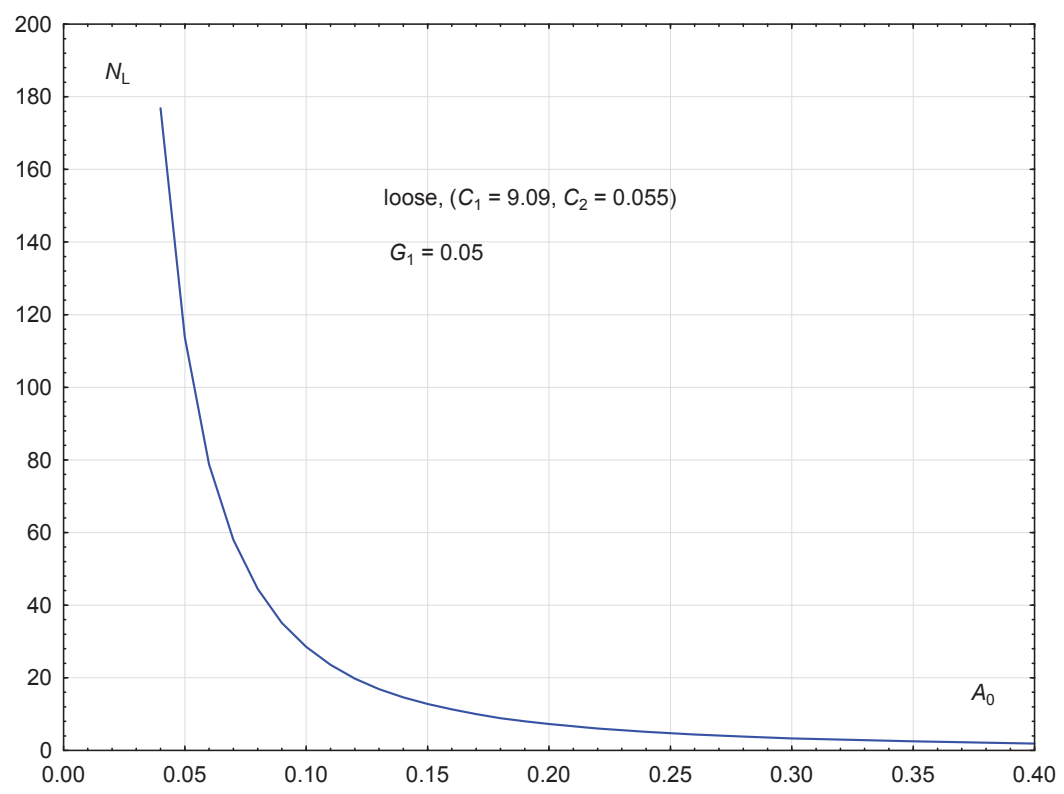

Fig. 8. Influence of the acceleration amplitude on the number of loading cycles to liquefaction

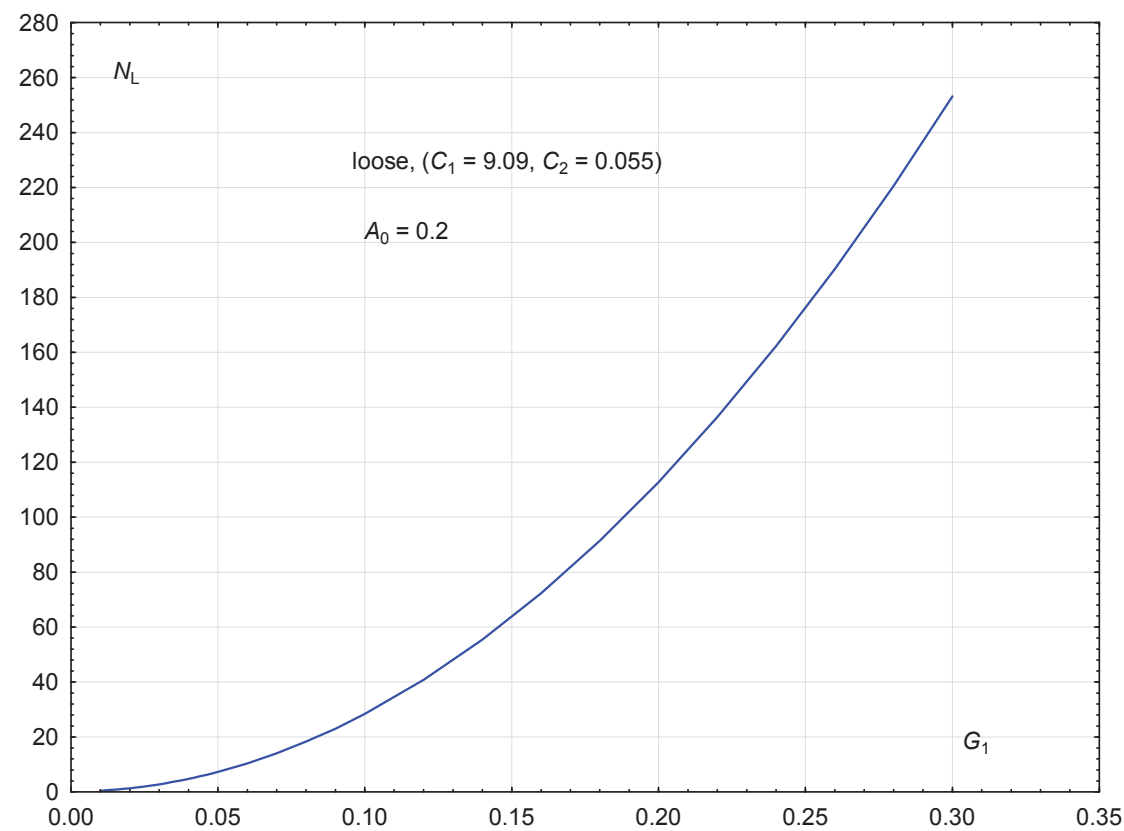

Fig. 9. Influence of the shear modulus on the number of loading cycles to liquefaction 
generated pore pressure is almost linear, which results from the character of the shaking table experiments described in this paper. Note that each layer of sand is subjected to the same acceleration because of the nature of the experimental device. There is no upwards propagation of shear waves from a rigid bedrock, as under real-life conditions, see SAWICKI \& ŚWIDZIŃSKI, [10]. Recall that under such conditions, liquefaction begins somewhere inside the layer, and then spreads downwards and upwards, depending on the intensity and history of bedrock shaking.

\section{Discussion AND CONCLUSIONS}

The results presented in this paper can be summarized as follows:

a. Numerical simulations of a sandy layer tested on the shaking table are shown. They include the settlements of a dry sandy layer, as well as the pore pressure generation and the subsequent liquefaction of a saturated sandy layer. The C/L model is applied in these simulations. The results of simulations are compared with selected experimental data.

b. It is shown that the $\mathrm{C} / \mathrm{L}$ model reasonably accurately describes the behavior of a layer tested, as it reproduces the average settlements of a dry layer, as well as the liquefaction of a saturated layer. The qualitative agreement is good, as the basic features of the sandy layer are captured.

c. The comparison of simulation results with experimental data is limited, because the above-mentioned processes were not recorded continuously. However, even such a limited comparison leads to the conclusion that a quantitative agreement of numerical simulations with experimental data is possible, provided that relevant material parameters are chosen properly.

d. For the above reason, some parametric studies are presented. The most sensible parameter is the shear modulus for small stresses. Further research on this issue is necessary.

\section{ACKNOWLEDGEMENT}

The research presented in this paper was supported by the National Research Council under the research project N N506 072938. 


\section{REFERENCES}

1. Fukutake K., Оhтsuki A., Sato M. \& Sнamoto Y. (1990): Analysis of saturated dense sand-structure system and comparison with results from shaking table test, Earthquake Engineering \& Structural Dynamics, 19, 7, 977-992.

2. Matsuo O., Tsutsumi T., Yokoyama K. \& Saito Y. (1998): Shaking table tests and analyses of geosynthetic-reinforced soil retaining walls, Geosynthetics International, 5, 1-2, 97-126.

3. Moretti M., Alfaro P., Caselles O. \& Canas J. A. (1999): Modelling seismites with a digital shaking table, Tectonophysics, 304, 4, 369-383.

4. Prasad S. K., Towhata I., Chandradhara G. P. \& Nanjundaswamy (2004): Shaking table tests in earthquake geotechnical engineering, Current Science, 87, 10, 1398-1404.

5. Seed H. B., Martin G. R. \& Pyke R. M. (1978): Effect of multidirectional shaking of pore pressure development in sands, Journal of the Geotechnical Engineering Division, ASCE, 104, 1, 27-44.

6. Towhata I., Vargas-Monge W., Orense R. P. \& Yao M. (1999): Shaking table tests on subgrade reaction of pipe embedded in sandy liquefied subsoil, Soil Dynamics \& Earthquake Engineering, 18, 5, 347-361.

7. Ueng T.-S., Wang M.-H., Chen M.-H., Chen C.-H. \& Peng L.-H. (2006): A large biaxial shear box for shaking table test on saturated sand, Geotechnical Testing Journal, ASTM, 29, 1, 1-8; Paper ID GTJ12649.

8. SAwICKI. A. (2012): An Outline of Mechanics of Granular Soils (in Polish), IBW PAN Editorial House, 214 pages.

9. SAwicki A., KulczyKowski M. \& J JNKowski R. (2012a): Estimation of stresses in a dry sand layer tested on shaking table, Archives of Hydro-Engineering \& Environmental Mechanics, 59, 101-112.

10. SAwicki A. AND Świdziński W. (2007): Simple mathematical model for assessment of seismic-induced liquefaction of soils, Journal of Waterway, Port, Coastal and Ocean Engineering, ASCE, 133, 1, 50-54.

11. SAwicki A., Mierczyński J. \& Świdziński W. (2012b): A basic set of experiments for the determination of mechanical properties of sands, accepted for publication in Bull. Pol. Ac. Sci. Tech. Sci.

12. SAwicki A., Świdziński W. \& Kulczyкowski M. (2012c): Shaking table dynamics of a dry sand layer, Proc. $2^{\text {nd }}$ Int. Conf. on Performance Based Design in Earthquake Geotechnical Engineering, Int. Soc. Soil Mech. Geotech. Eng., Taormina (Italy), 661-668. 